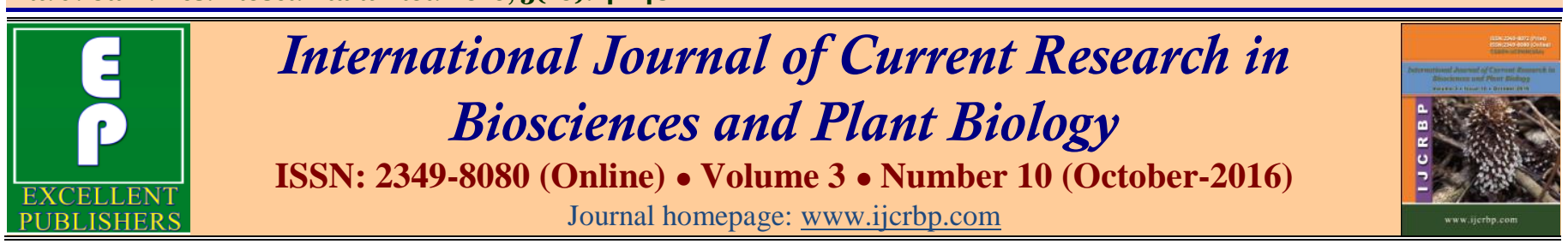

\title{
Cloning and Sequence Analysis of a Chalcone Synthase (CHS) Gene Involved in Anthocyanin Biosynthesis in Prunus persica
}

\author{
Jiabao Ye, Xianghong Yang, Qiangwen Chen, Tingting Tao, Guiyuan Wang and Feng Xu*
}

College of Horticulture and Gardening, Yangtze University, Jingzhou 434025, China

*Corresponding author.

\begin{abstract}
A bstract
Flavonoids are a kind of important secondary metabolites in plants. Usually, it was found in fruits, vegetables, beans, tea and many other plants as combination (flavonoid glycosides) or free states (flavonoid glycosides) form. It has important role in regulating plant growth and development. Chalcone synthase (CHS, EC 2.3.1.74), the first key synthase during the process of flavonoids synthesis, plays an important role in plant growth and development. Based on the whole peach genome sequence, the full length cDNA sequence of chalcone synthase gene (CHS) from Prunus persica was isolated by RT-PCR technology. This sequence was $1254 \mathrm{bp}$, and it included an open reading frame of $1032 \mathrm{bp}$ corresponding to 344 amino acids, and the molecular weight was $37.75 \mathrm{kDa}$, with the isoelectric point of 5.43 , which was designated as PpCHS (GenBank accession No. KX823936). Bioinformatics analysis showed that the deduced PpCHS, which shared more than 79\% identities with the CHS protein from other plants, was predicted to possess the conserved CHS_like domain, active sites and signal sequences. In the evolutionary tree could be seen the Fragaria vesca subsp. vesca and Morus notabilis genetic relationship is close. The result implied the properties of CHS in the Prunus persica was almost as the same as them of other plants. These results indicate that PpCHS belongs to CHS families and provide the basis of research the enzymes and their genes in further step.
\end{abstract}

\section{Introduction}

Prunus persica is a deciduous tree native to the region of Northwest China between the Tarim Basin and the north slopes of the Kunlun mountain, where it was first domesticated and cultivated (Faust et al., 1995). It bears an edible juicy fruit called a peach or a nectarine. Some 110 chemical compounds contribute to peach aroma, including alcohols, ketones, aldehydes, esters, polyphenols and terpenoids (Sánchez et al., 2012). Surface color changes of the peach fruit was one of the important indexes for the evaluation of the appearance

\section{Article Info}

Accepted: 11 September 2016

Available Online: 06 October 2016

\section{Keywords}

Bioinformatic analysis

Chalcone synthase

Function domains

Prunus persica quality of peach fruit, corresponding color conditions will have a direct influence in their commercial value. The research on the anthocyanin accumulation in the peach fruit generally includes bagging and hormone spraying, etc., but studies on the molecular mechanism of peach fruit color formation are relatively little at present.

Flavonoids are secondary metabolites of plants, which play a decisive role in flower colors, and are suggested to be antioxidant, enzyme inhibitor, plant growth regulator and antitoxin in plants. In addition, flavonoid is one of 
the most important components of traditional Chinese medicinal plant, having antioxidant, improvement of human immunity, anti-cancer and other effects on the human body (De León et al., 2007; Courtney-Gutterson et al., 1994). Chemical compounds such as anthocyanin, proanthocyanidins and phlobaphenes are the principal components of plant pigments, which are produced through flavonoid biosynthesis pathway in plants (Winkel-Shirley et al., 2001).

Chalcone synthase (CHS) is the first key enzyme within the synthesis pathway of flavonoids, which is also the first key enzyme in the biosynthesis pathway of peach fruit anthocyanin (Dao et al., 2011). It is responsible for the catalysis of the first step of such pathway, namely, resulting in the catalytic condensation generation of chalcone from termolecular malonyl-CoA and unimolecular 4-coumaroyl-CoA (Hashimoto et al., 1995). Following the isomerization of chalcone, final biosynthesis of anthocyanins is achieved under the action of the enzyme, such as: chalcone isomerase, flavanone $3 \beta$-hydroxylase, dihydroflavonol-4-reductase, anthocyanins synthase, and UDP-Glc: flavonoid-3-Oglucosyltransferase. The pathway of flavonoid in peach leading to anthocyanin synthesis is given in Fig. 1.

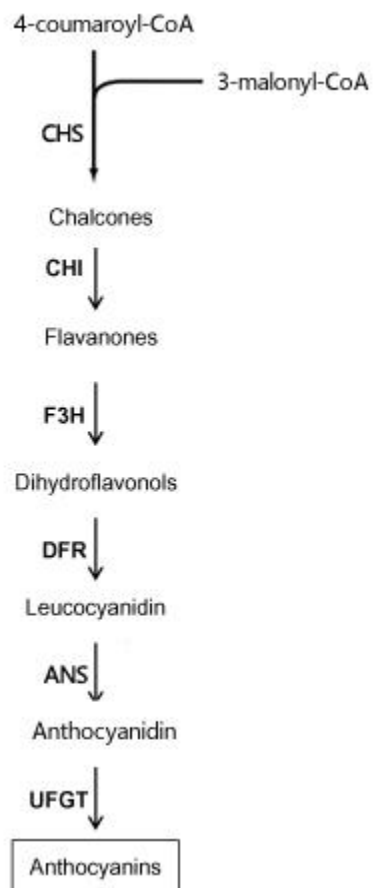

Fig. 1: Schematic diagram of the flavonoid pathway in peach leading to the synthesis of anthocyanins. The enzymes are shown in capital letters and are: CHS, chalcone synthase; $\mathrm{CHI}$, chalcone isomerase; $\mathrm{F} 3 \mathrm{H}$, flavanone $3 \beta$-hydroxylase; DFR, dihydroflavonol-4-reductase; ANS, anthocyanins synthase; UFGT, UDP-Glc:flavonoid-3-O-glucosyltransferase.
Since the publication of the first CHS sequence of parsley in 1972 (Kreuzaler et al., 1972), scientists have cloned the CHS gene sequence from a variety of plants, such as Arabidopsis thaliana (Saslowsky et al., 2000), Glycine max (Linn.) Merr (Kurauchi et al., 2011); Medicago sativa L. (McKhann et al., 1994), Pinus (Schröder et al., 1998), Petunia hybrida Vilm (Holton et al., 1993), Physcomitrella patens (Koduri et al., 2010), Cymbidium ssp. (Liew et al., 1998), Hordeum vulgare L. (Rohde et al., 1991), and Antirrhinum majus L. (Sommer et al., 1986). But so far, there has not been a report on the complete CHS sequence and expression analysis of peach peel, up till the present moment. Furthermore, many researches relevant to CHS gene have focused on this field since flavonoids are closely related to plant flowers and fruit pigmentation.

In the present study, on the basis of whole genome information of peach trees, RT-PCR technology was applied to clone the full-length cDNA of $\mathrm{PpCHS}$ sequence from the peach peel for the first time, meanwhile, corresponding open reading frame, homology and phylogenetic trees were further analyzed by bioinformatics tools including DNAMAN, BlAST, and MEGA, so as to construct the expression vector of peach plants in the next step, and to provide basic data for studying the mechanism of expression and regulation of this gene.

\section{Materials and methods}

\section{Plant materials}

The peach was grown in the horticultural farm of Yangtze University, China. DNA and RNA extraction were collected from peach peels, immediately put them in the liquid nitrogen, and then were stored at Ultra-Low Temperature Freezer type (DW-86L626, Haier Co. Ltd., China) until use.

\section{DNA and RNA extraction}

Fruit peel of peach weighing $2 \mathrm{~g}$ were immediately ground to powder in liquid nitrogen, filtered and after that centrifuged at $10,000 \mathrm{rpm}$ for $10 \mathrm{~min}$. Total RNA was extracted from the pericarps of peach tissues using MiniBEST Plant RNA Extraction kit (TaKaRa, China). Genomic DNA of the peach peel was extracted by the MiniBEST Bacterial Genomic DNA Extraction Kit Ver.2.0 (TaKaRa, China). The purity, concentration, and quality of the total RNA and DNA were tested by $1 \%$ $(w / v)$ agarose gel electrophoresis before using. 


\section{cDNA synthesis}

First-strand cDNA of peach was synthesised with using cDNA Prime Script ${ }^{\circledR}$ 1st Strand cDNA Synthesis Kit (TaKaRa, China). Reaction system contained Oligo dT Primer $2 \mu \mathrm{l}$, dNTP mixture $2 \mu \mathrm{l}$, Total RNA $16 \mu \mathrm{l}$; $5 \times$ Primscript buffer $8 \mu 1$, RNase inhibitor $1 \mu 1$, Prime script RTase $2 \mu \mathrm{l}$, RNA free $\mathrm{H}_{2} \mathrm{O} 9 \mu \mathrm{l}$; under the following conditions: $45^{\circ} \mathrm{C}$ for $30 \mathrm{~min}$, followed by $75^{\circ} \mathrm{C}$ for $20 \mathrm{~min}$.

\section{Isolation of the full-length cDNA of PpCHS}

The primers CHS-FP (5'-ACTACACATATAGACTGCGCATG-3') and CHS-RP (5'-GATATAGGCTTAGACAGCAAGG-3') were designed and synthesized (Sangon, China) based on the EST sequence of the peach CHS gene. The PCR reaction contained $1 \mu \mathrm{l}$ cDNA products, $2.5 \mu \mathrm{l} 10 \times$ buffer, $2.0 \mu 1$ $\mathrm{MgCl}_{2}, 0.5 \mu \mathrm{l}$ TaqDNA polymerase, $1.0 \mu \mathrm{l}$ dNTP mix and $18 \mu \mathrm{l} \mathrm{ddH}_{2} \mathrm{O}$ up to $25 \mu \mathrm{l}$. The following conditions: and $96^{\circ} \mathrm{C}$ for $3 \mathrm{~min}$, followed by 33 cycles of amplification at $96^{\circ} \mathrm{C}$ for $50 \mathrm{~s}, 56^{\circ} \mathrm{C}$ for $50 \mathrm{~s}$, and $72^{\circ} \mathrm{C}$ for 70s. This was followed by extension for $5 \mathrm{~min}$ at $72^{\circ} \mathrm{C}$. The PCR product was purified, cloned into the pMD20-T vector (TaKaRa, China), and then sequenced.

\section{Bioinformatics and molecular evolution analyses}

The obtained nucleotide sequence and deduced amino acid sequence were compared through database search using online bioinformatics tools (NCBI, http://www.ncbi.nlm.nih.gov). Multiple sequence alignment was performed by using the website (http://multalin.toulouse.inra.fr/multalin/). The software DNAman 5.0 was used to analyze $P p C H S$ gene sequence and amino acid composition. PpCHS and other CHS proteins obtained from GenBank were aligned with the software Vector NTI suit 10.0 program. Phylogenetic tree was constructed by were analyzed using BioEdit 5.0 and MEGA 6.0. The reliability of the tree was measured by bootstrap analysis with 100 replicates. Gene Infinity tool (http://www.geneinfinity.org/index.html) was used to deduce protein isoelectric point $(\mathrm{pI})$ and molecular weight (MW).

\section{Results}

\section{cDNA cloning of $\mathrm{PpCHS}$}

Based on the sequences of EST, the cDNA sequence of PpCHS was obtained according to a pair of specific primers and total RNA reverse transcription product. The length of the cDNA sequence of $P p C H S$ is $1254 \mathrm{bp}$, and the open reading frame is $1032 \mathrm{bp}$ encoding 344 amino acids (Fig. 2). The cDNA sequence of PpCHS had high similarity with other CHS genes, and the $\mathrm{G}+\mathrm{C}$ content of $\mathrm{PpCHS}$ sequence is $45 \%$.

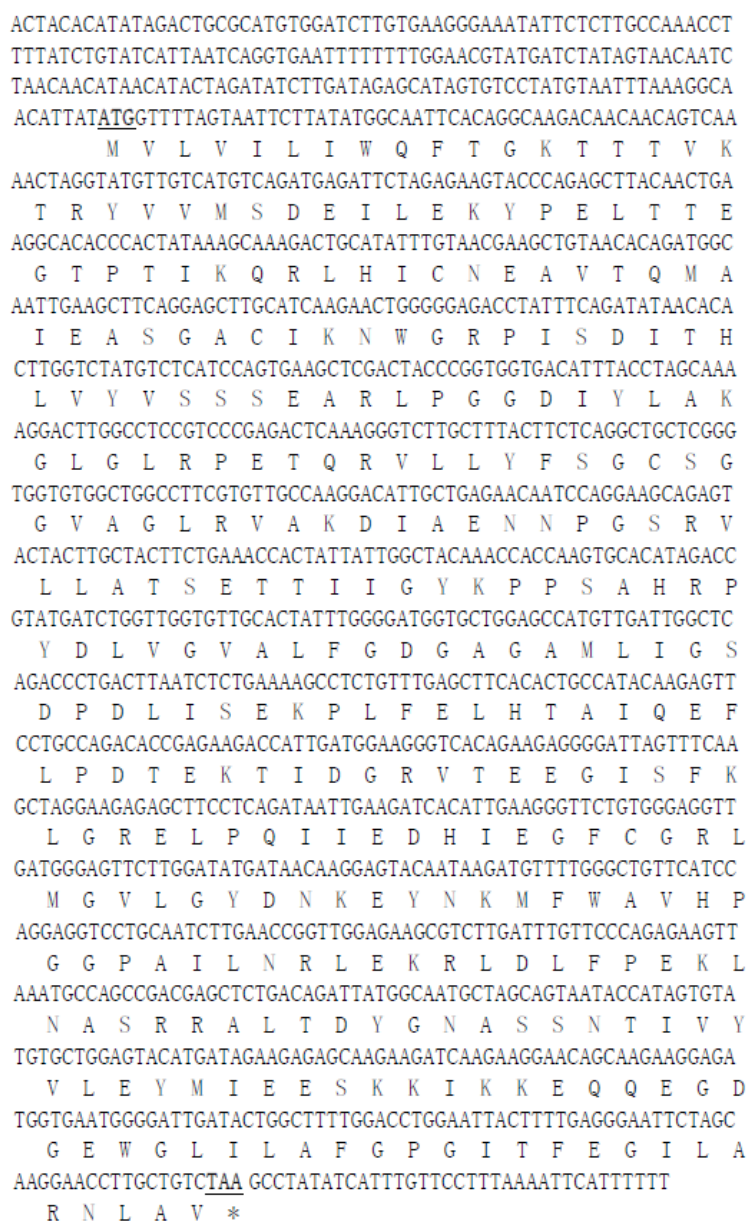

Fig. 2: Nucleotide sequence and deduced amino acid sequence of $\mathrm{PpCHS}$.

\section{Characterization of the deduced PpCHS protein}

Through analysis with the Computer $\mathrm{pI} / \mathrm{MW}$, we found the molecular weight was $37.75 \mathrm{kDa}$ and isoelectric point of 5.43. Blastp aligning analysis found the deduced PpCHS protein has CHS_like, region, and conserved FabH and PLN03169 domains, with a cond_enzymes superfamily (Fig. 3). The cloned PpCHS belongs to CHS superfamily. The secondary structures of CHS proteins were predicted by using SOPMA tool. It was found that PpCHS contents extensive alpha helix (Hh) 31.78\%, extended strand (Ee) 26.24\%, random coil (Cc) $32.36 \%$ and beta turn (Tt) $9.62 \%$ (Fig. 4). The secondary structures of deduced PpCHS had high similarities with Silene latifolia, Morus notabilis, and Brassica napus CHS proteins (Table 1). 


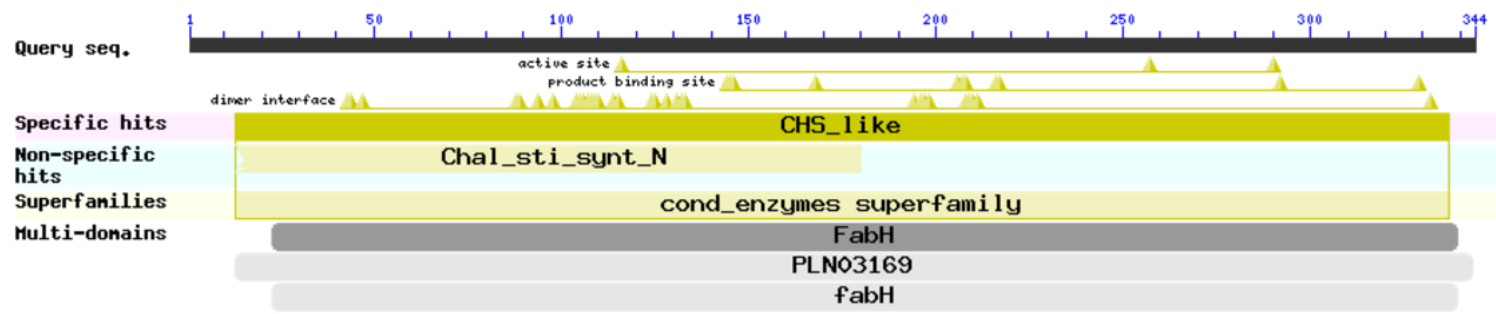

Fig. 3: The amino acid conservative sequence analysis of PpCHS. Non-specific hits is the most conserved domain model matching with the query sequence; A superfamily cluster is a set of conserved domain models that generate overlapping annotation on the same protein sequences; Multi-domains are domain models that contain multiple single domains.
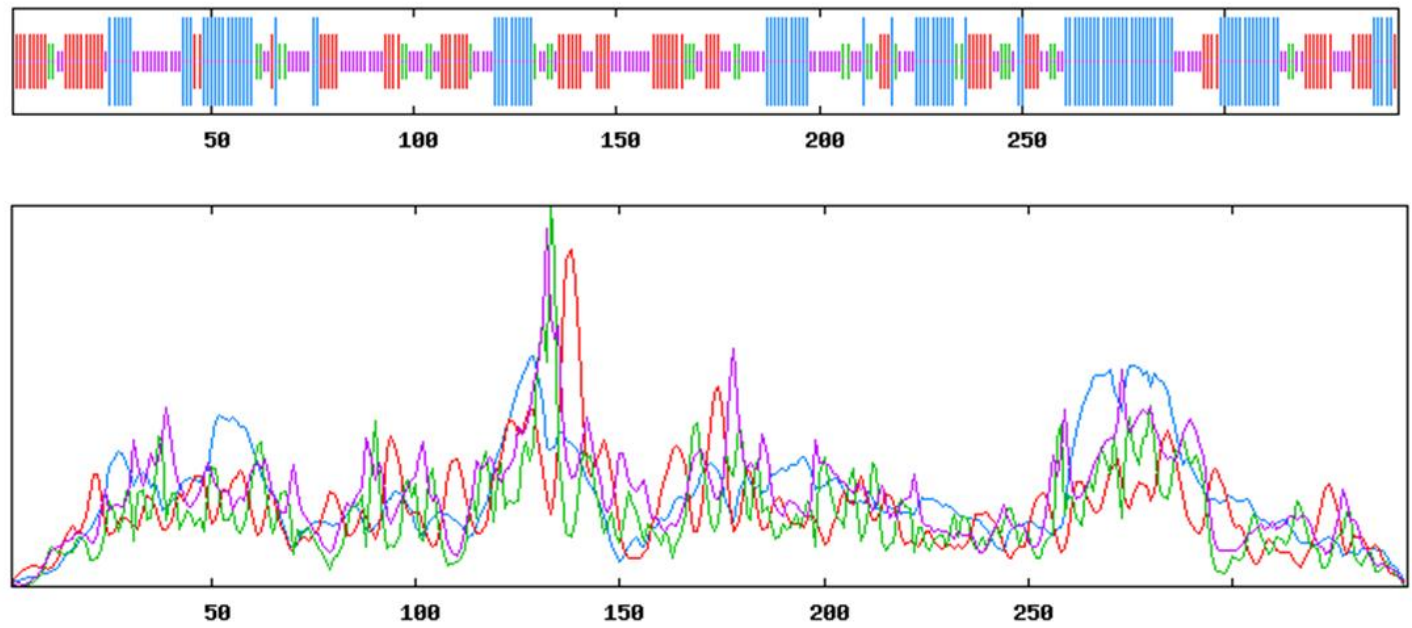

Fig. 4: The predicted secondary structures of PpCHS protein.

Table 1. Secondary structure of CHS proteins (unit: \%).

\begin{tabular}{lllll}
\hline Species & Alpha helix (Hh) & Extended strand (Ee) & Random coil (Cc) & Beta turn (Tt) \\
\hline Prunus persica & $31.78 \%$ & $26.24 \%$ & $32.36 \%$ & $9.62 \%$ \\
Silene latifolia & $34.30 \%$ & $23.22 \%$ & $32.72 \%$ & $9.76 \%$ \\
Morus notabilis & $38.68 \%$ & $19.34 \%$ & $30.03 \%$ & $11.96 \%$ \\
Brassica napus & $36.22 \%$ & $20.92 \%$ & $30.87 \%$ & $11.99 \%$ \\
\hline
\end{tabular}

\section{Multiple alignments of PpCHS protein}

Using BLAST search of GeneBank and Vector NTI, as shown in Fig. 5, the PpCHS protein had higher homology with other CHS proteins. The amino acid sequences multiple sequence alignment showed that PpCHS had high identities with Glycine soja CHS (85\% identities, KHN32314.1), Cajanus cajan CHS (84\% identities, KYP68086.1), Morus notabilis CHS (83\% identities, EXB36843.1), Arabidopsis thaliana CHS (80\% identities, ABK28665.1), Brassica napus CHS (80\% identities, CDY58814.1), Silene latifolia CHS (80\% identities, BAE80096.1) and Cynara cardunculus var. scolymus CHS (79\% identities, KVH96005.1). The above analysis shows that PpCHS was a member of the CHS family.

\section{Phylogenetic tree analysis of PpCHS}

To investigate the evolutionary relationships in PpCHS and CHSs from other plant species, a phylogenetic tree was constructed by using MEGA 6.0. As shown in Fig. 6, phylogenetic analysis of CHS showed that PpCHS have a closer relationship to Fragaria vesca subsp. vesca CHS protein than to other CHS proteins. The results showed that the PpCHS protein together with Glycine soja, Cajanus cajan, Arabidopsis thaliana, and Brassica napus were grouped into a functional cluster. The above results showed that PpCHS belonged to CHS gene family. 


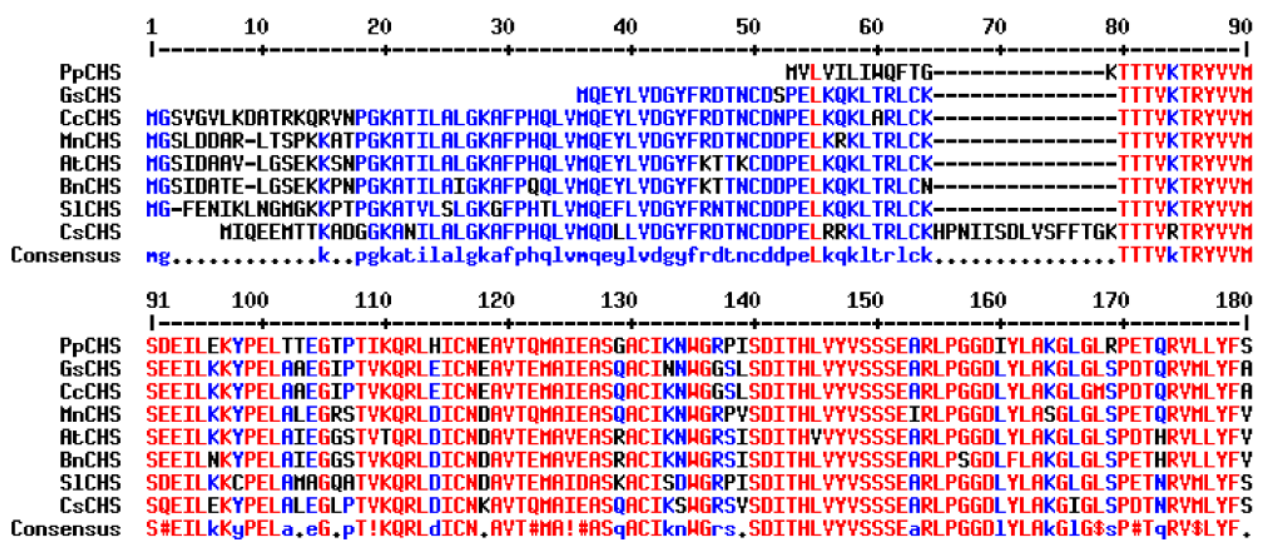

Consensus S\#EILkKyPELa,eG,PT!KQRLdICN,AYT\#HA! \#ASqACTknHGrs,SDITHLYYYSSSEaRLPGGDIYLFkG1G\$sP\#TqRY\$LYF.

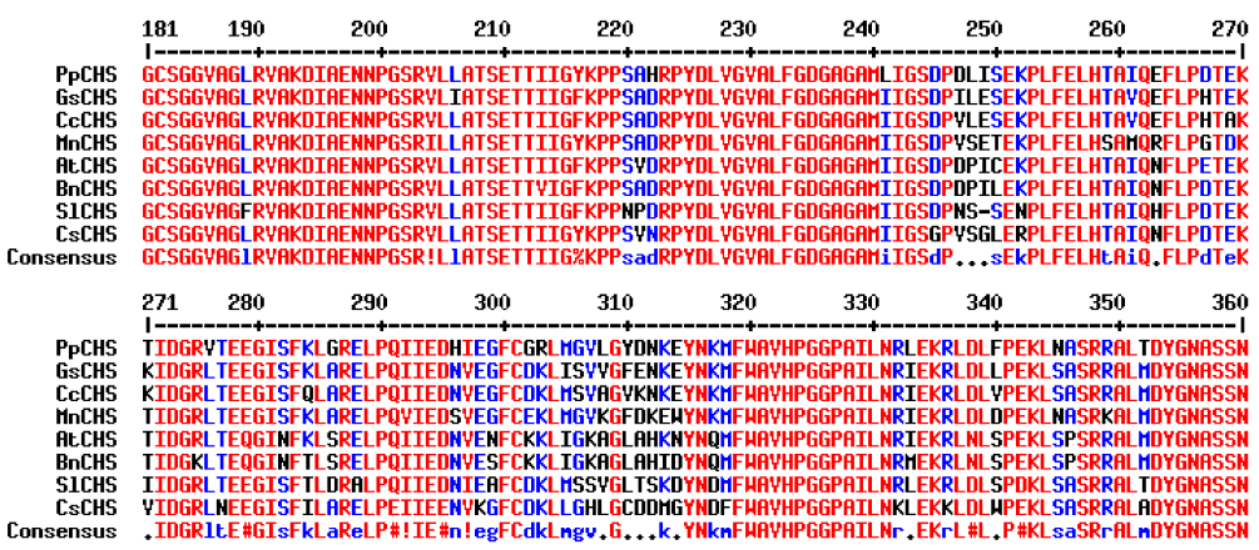

Consensus .IDGRItE\#GIsFkLaReLP\#!IE\#n! egFCdkLngv,G...k. YNknFHAYHPGGPAILNr. EKrL \#L.P\#KLsaSRrFLnDYGNASSN

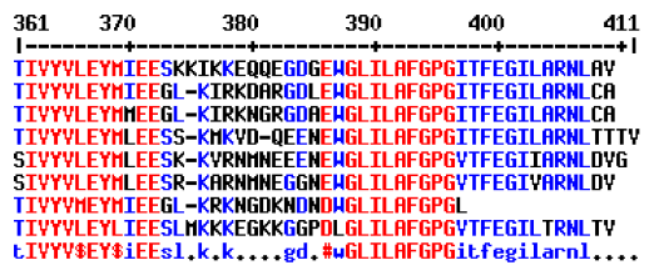

Fig. 5: Sequence multialignment of the deduced PpCHS protein with other plant chalcone synthases. Alignment of some plant Chalcone synthase sequences available on GenBank. Prunus persica, PpCHS; Glycine soja, GsCHS, KHN32314.1; Cajanus cajan, CcCHS, KYP68086.1; Morus notabilis, MnCHS , EXB36843.1; Arabidopsis thaliana, AtCHS, ABK28665.1; Brassica napus, BnCHS, CDY58814.1; Cynara cardunculus var. scolymus, CsCHS, KVH96005.1; Silene latifolia, CsCHS, KVH96005.1; Silene latifolia, SICHS, BAE80096.1.

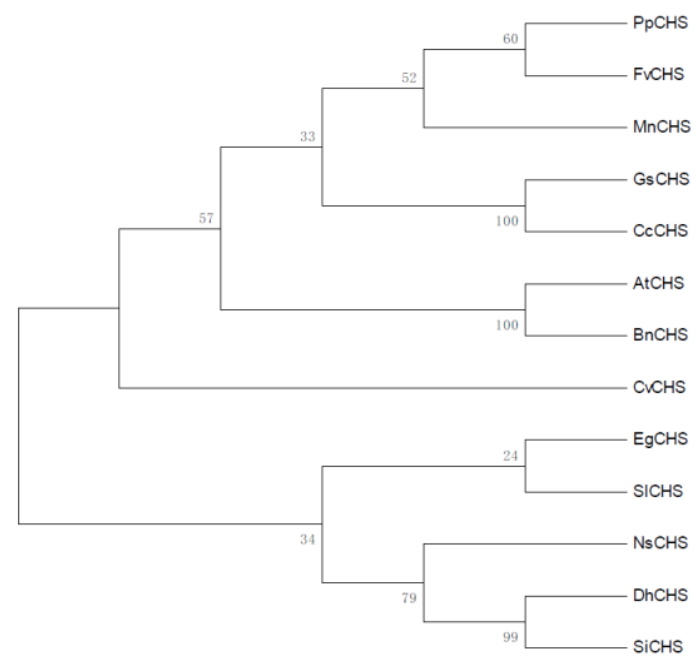

Fig. 6: Phylogenetic analysis of plant secondary product chalcone synthases. The number for each interior branch is the percent bootstraps value (1000 replicates). GenBank accession number are as follows: Prunus persica, PpCHS; Fragaria vesca subsp. vesca, FvCHS, XP_004289833.1; Dorcoceras hygrometricum, DhCHS, KZV22002.1; Glycine soja,GsCHS, KHN32314.1; Cajanus cajan, CcCHS, KYP68086.1; Morus notabilis, MnCHS, EXB36843.1; Eucalyptus grandis, EgCHS, XP_010028685.1; Nicotiana sylvestris, NsCHS, XP_009799363.1; Sesamum indicum, SiCHS, XP_011092869.1; Arabidopsis thaliana; AtCHS, ABK28665.1; Brassica napus BnCHS, CDY58814.1; Cynara cardunculus var. scolymus, CvCHS, KVH96005.1; Silene latifolia, SICHS, BAE80096.1. 


\section{Discussion}

Chalcone synthase is the first enzyme in biosynthesis pathway of anthocyanin, the catalytic formation of chalcone is a precursor of various pigments in the metabolic pathways of anthocyanin, corresponding activity directly affects the downstream reaction, and ultimately produces a significant effect on the yield of flavonoids (Shelagh et al., 2001). This study isolated a CHS gene from peach fruit peel by using RT-PCR technique. Results show that the full-length cDNA of $P p C H S$ was $1254 \mathrm{bp}$ containing a $1032 \mathrm{bp}$ open reading frame (ORF) encoding 344 amino acids with a calculated molecular mass of $37.75 \mathrm{kDa}$ and an isoelectric point of 5.43. Blastp aligning analysis found the deduced PpCHS protein has CHS_like, region, and conserved FabH and PLN03169 domains, with a cond_enzymes superfamily. The secondary structures of deduced PpCHS had high similarities with Silene latifolia, Morus notabilis, and Brassica napus CHS proteins. The results of nucleic acid homology alignment revealed that the homology of CHS in Prunus persica was very high with other plants. It was found that the PpCHS gene encoding for the protein had close relationship with Fragaria vesca subsp. vesca through phylogenetic analysis. The above results show that the PpCHS protein belonged to CHS proteins family, with synthetase chalcone catalytic function.

Flavonoids are the largest class of secondary metabolites existed in the nature, more than 5000 kinds are known at present, most of them have colors, acting as the main component of plant pigments (Winkel-Shirley et al., 2001). As one of the important secondary metabolic pathways in plants, the regulation system of phenylalanine metabolism pathway is very complex, not only influenced by the control of the body gene, but also affected by the external conditions. Chalcone synthase is a popular element in numerous plants, which plays an important role in the antimicrobial mechanism, stress resistance, cell development and differentiation, the accumulation of pigments and the expression of exogenous genes (Koes et al., 1989).

The activity of chalcone synthase affects the level of the synthesis of flavonoids in plant body, in this regard, the improvement of the expression of plant chalcone synthase gene can promote chalcone synthase activity, which indirectly influence the synthesis of chalcone to provide raw materials for the synthesis of flavonoids. The CHS gene is a super-gene family, the expression patterns of different members are not the same. Plant CHS gene expression is influenced by the stage of plant development and the external environment (Han et al., 2006). Many studies have shown that the CHS gene was actively transcribed when the plant was infected by pathogenic bacteria, wound, UV radiation and exogenous hormones, corresponding activity was markedly increased. Previous research also suggested that the CHS expression was significantly increased after barley, beans, broccoli and so on were infected by pathogenic bacteria (Christensen et al., 1998; Richard et al., 2000).

It has been reported that the yield of the secondary metabolites can be increased by changing the expression of key enzymes in the synthesis pathway of plant secondary metabolites. For example, anthocyanin yield in the sweet wormwood with over expressed CHS gene improved fourfold compared to that in the controls (Chen et al., 1999); The results of the researches showed that following the overexpression of CHS from the yeast in tobacco, anthocyanin yield was obviously improved (Daudonnet et al., 1997). If the expression of CHS gene is increased in peach tree, it is possible to increase the content of anthocyanin in peel and hence improve the quality of fruit. However, currently the transgenic system of peach is not mature, besides, it is difficult to overexpress the CHS gene in peach through biotechnology. Even though, based on the in-depth study of the expression and regulation mechanism of $P p C H S$, it is possible to regulate the expression of $P p C H S$ by means of hormone or chemical regulation to increase the yield of anthocyanin. On the other hand, this study lays a theoretical foundation for the study of molecular biology on peach peel pigmentation, as well as peach quality improvement and breeding at the molecular level.

\section{Conclusion}

PpCHS containing a 1032 bp ORF, encoding 344 amino acids with a calculated molecular mass of $37.75 \mathrm{kDa}$ and an isoelectric point of 5.43 was isolated by RT-PCR from Prunus persica. The amino acids of PpCHS protein has CHS_like region, and conserved FabH and PLN03169 domains, with a cond_enzymes superfamily. The phylogenetic tree analysis demonstrated the PpCHS protein was grouped with Fragaria vesca subsp. vesca. The above results suggest that the PpCHS is likely to participate in regulating the anthocyanin biosynthetic pathway of flower and fruit in Prunus persica.

\section{Conflict of interest statement}

Authors declare that they have no conflict of interest. 


\section{Acknowledgement}

This current research was supported by National Natural Science Foundation of China (No. 31300574).

\section{References}

Chen, D.H., Liu, C.J., Ye, H.C., 1999. Ri-mediated transformation of Artemisia апnиa with a recombinant farnesyl diphosphate synthase gene for artemisinin production. Plant Cell Tiss. Org. Cult. 57, 157-162.

Christensen, A.B., Gregersen, P.L., Schröder, J., Collinge, D.B., 1998. A chalcone synthase with an unusual substrate preference is expressed in barley leaves in response to UV light and pathogen attack. Plant Mol. Biol. 37(5), 849-857.

Courtney-Gutterson, N., Napoli, C., Lemieux, C., Morgan, A., Firoozabady, E., Robinson K.E., 1994. Modification of flower color in florist's chrysanthemum: production of a white-flowering variety through molecular genetics. Biot. 12(3), 268-271.

Dao, T.T.H., Linthorst, H.J.M., Verpoorte, R., 2011. Chalcone synthase and its functions in plant resistance. Phytochem. Rev. 10(3), 397-412.

Daudonnet, S., Karst, F., Tourte, Y., 1997. Expression of the farnesyl diphosphate synthase gene of Saccharomyces cerevisiae in tobacco. Mol. Breeding. 3, 137-145.

De León I.P., Oliver J.P., Castro A., Gaggero C., Bentancor M., Vidal, S., 2007. Erwinia carotovora elicitors and Botrytis cinerea activate defense responses in Physcomitrella patens. BMC Plant Biol. 7, 52.

Faust, M., Timon, B., 1995. Origin and dissemination of peach. Hort. Rev. 17, 331-379.

Han, Y.Y., Ming, F., Wang, W., Wang, J.W., Ye, M.M., Shen, D.L., 2006. Molecular evolution and functional specialization of chalcone synthase superfamily from Phalaenopsis orchid. Genetica. 128(1-3), 429-438.

Hashimoto, Y., Ishizaki, T., Shudo, K., 1995. Chemistry of benzoxazinoids produced by plants as phytoalexin. Yakugaku Zasshi. 115(3), 189-200.

Holton, T.A., Brugliera, F., Tanaka, Y., 1993. Cloning and expression of flavonol synthase from Petunia hybrida. Plant J. 4 (6), 1003-1010.

Kreuzaler, F., Hahlbrock, K., 1972. Enzymic synthesis of aromatic compounds in higher plants: formation of naringenin (5, 7, 4'-trihydroxy-flavanone) from $\mathrm{p}$ coumaroyl-coenzyme A and malonyl-coenzyme A. FEBS Lett. 28, 69-72.

Koes, R.E., Spelt, C.E., van den Elzen, P.J., Mol, J.N., 1989. Cloning and molecular characterization of the chalcone synthase multigene family of Petunia hybrida. Gene. 81(2), 245-257.

Koduri, P.H., Gordon, G.S., Barker, E.I., Colpitts, C.C., Ashton, N.W., Suh, D.Y., 2010. Genome-wide analysis of the chalcone synthase superfamily genes of Physcomitrella patens. Plant Mol. Biol. 72(3), 247-263.

Kurauchi, T., Kasai, A., Tougou, M., Senda, M., 2011. Endogenous RNA interference of chalcone synthase genes in soybean: Formation of double-stranded RNA of GmIRCHS transcripts and structure of the $5^{\prime}$ and $3^{\prime}$ ends of short interfering RNAs. Plant Physiol. 168(11), 12641270.

Liew, C.F., Goh, C.J., Loh, C.S., Lim, S.H., 1998. Cloning and characterization of full-length cDNA clones encoding chalcone synthase from the orchid Bromheadia finlaysoniana. Plant Physiol. Bioch. 36(9), 647-656.

McKhann, H.I., Hirsch, A.M., 1994. Isolation of chalcone synthase and chalcone isomerase cDNAs from alfalfa (Medicago sativa $\mathrm{L}$.): highest transcript levels occur in young roots and root tips. Plant Mol. Biol. 24(5), 767-777.

Richard, S., Lapointe, G., Rutledge, R.G., Séguin, A., 2000. Induction of chalcone synthase expression in white spruce by wounding and jasmonate. Plant Cell Physiol. 41(8), 982-987.

Rohde, W., Dorr, S., Salamini, F., 1991. Structure of a chalcone synthase gene from Hordeum vulgare. Plant Mol. Biol. 16(6), 1103-1106.

Saslowsky, D.E., Dana, C.D., Winkel-Shirley, B., 2000. An allelic series for the chalcone synthase locus in Arabidopsis. Gene. 255(2), 127-138.

Sánchez, G., Besada, C., Badenes, M.L., Monforte, A.J., Granell, A., 2012. A non-targeted approach unravels the volatile network in peach fruit. PloS One. 7(6), e38992.

Schröder, J., Raiber, S., Berger, T., Schmidt, A., Schmidt, J., Soares-Sello, A.M., Schröder, G., 1998. Plant polyketide synthases: A chalcone synthase-type enzyme which performs a condensation reaction with methylmalonyl$\mathrm{CoA}$ in the biosynthesis of C-methylated chalcones. Bioch. 37(23), 8417-8425.

Shelagh, R.M., Geoff, J.C., Susan, R., 2001. Over-expression of petunia chalcone isomerase in tomato results in fruit containing increased levels of flavonols. Nat. Biot. 19, 470-474.

Sommer, H., Saedler, H., 1986. Structure of the chalcone synthase gene of Antirrhinum majus. Mol. Gen. Genet. 202(3), 429-434.

Winkel-Shirley, B., 2001. Flavonoid biosynthesis. A colorful model for genetics, biochemistry, cell biology, and biotechnology. Plant Physiol. 126(2), 485-493.

\section{How to cite this article:}

Ye, J., Yang, X., Chen, Q., Tao, T., Wang, G., Xu, F., 2016. Cloning and sequence analysis of a chalcone synthase (CHS) gene involved in anthocyanin biosynthesis in Prunus persica. Int. J. Curr. Res. Biosci. Plant Biol. 3(10), 42-48. doi: http://dx.doi.org/10.20546/ijcrbp.2016.310.006 